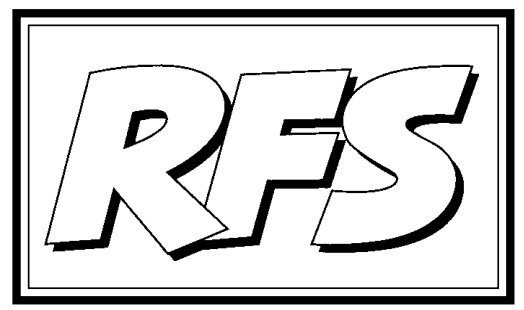

Revista de Fomento Social, 54 (1999), 289-308

\title{
¿Es posible la «tercera vía»?
}

Consejo de Redacción

Este artículo editorial quiere plantear una pregunta más que ofrecer una respuesta. Por eso el título que hemos escogido va entre signos de interrogación.

Pero hasta la pregunta es discutible en su formulación. Porque para hablar de «tercera vía» habría que contar con otras dos. En realidad, no existe más que una: la que se ha impuesto por todas partes, tras el colapso del colectivismo y la crisis aguda del Estado de bienestar. Ese modelo, inspirado en la tradición liberal aunque interpretada de forma muy radicalizada, es el que sirve de base, con más o menos variantes, para la organización socioeconómica en casi todos los países del planeta.

¿Por qué se ha escogido la expresión «tercera vía»? El término no es nuevo. Ya a comienzos del presente siglo lo empleó la Iglesia católica en su intento de buscar una vía media (tercera) entre capitalismo y socialismo. Luego se ha usado en diferentes ocasiones: el último fue quizás Enrico Berlinguer, a principios de los setenta, para presentar el eurocomunismo como un tercer camino entre el modelo soviético y la socialdemocracia europea.

Quizás esta pretensión de encontrar alternativa es la que explica que el 
término haya sido recuperado por políticos de tradición socialdemócrata (Blair, Schröder, Jospin...) con el deseo de ofrecer una propuesta de refundación de la izquierda en el umbral del nuevo siglo. Por eso, para entender lo que podría ser esa «tercera vía» hay que comenzar remontándose a la historia del socialismo y a su evolución hacia la socialdemocracia.

\section{Un poco de historia}

\section{Del socialismo utópico a la socialdemocracia}

El socialismo nació en el primer tercio del siglo XIX como una crítica radical al capitalismo liberal que se consolidaba en buena parte de Europa. Su radicalismo era el correlato natural a las condiciones de miseria en que se debatía buena parte de la clase trabajadora industrial de esos países. Los primeros socialistas - a los que más tarde Marx llamaría despectivamente «socialistas utópicos»-proponían cosas tan sorprendentes para nosotros hoy como dividir la tierra en pequeñas parcelas para que todos pudieran ser propietarios, suprimir la herencia para que todos comenzasen de cero o conceder créditos bancarios sin interés. Esta simple enumeración de propuestas permite comprender que para aquellos autores (Babeuf, Saint-Simon, Fourier, Blanc, Blanqui, Owen, Cabet, Proudhon...) la raíz de todos los problemas estaba en la propiedad privada de los medios de producción y en los mecanismos que favorecían la acumulación de bienes en pocas manos.

Marx se esforzó por apartarse de esas «utopías» y entrar en un análisis más concienzudo de la realidad estudiando los mecanismos del sistema económico vigente (al que todavía no se llamaba «capitalismo»). Por ese camino llegó a detectar lo que para él eran las contradicciones inherentes al sistema, en las que veía como un germen que llevaría al capitalismo a su propia aniquilación. La dimensión revolucionaria de su análisis estaba más bien en la estrategia de lucha que proponía, consistente en acelerar las contradicciones para precipitar el final. Su diagnóstico no fue acertado, pero ello no es óbice para reconocer que en Marx - al margen de sus cualidades como filósofo y analista social y económico-había más de poderoso líder de masas que de utópico empedernido.

Los seguidores de Marx se dividirían por sus desacuerdos irreconciliables, no sobre la necesidad de buscar una alternativa al capitalismo, sino sobre la 
vía más adecuada para conseguirlo. Los «socialistas» pretenderían el cambio utilizando los medios democráticos, mientras que los comunistas optarían por el levantamiento revolucionario. Adónde lle gó el comunismo lo sabemos por los acontecimientos de 1989. Aunque no carece de interés profundizar en el camino que condujo a su crisis final, nos interesa más en este momento seguir la pista del socialismo, porque es ella la que nos conducirá a la «tercera vía».

El capitalismo mixto, vía media entre el capitalismo liberal y el colectivismo comunista

Quizás la transformación de más calado que sufrió el socialismo fue la que le condujo a modificar su postura inicial de rechazo total del capitalismo. Este cambio tiene que ver con el abandono del marxismo, aunque no se diera simultáneamente. La socialdemocracia alemana lo haría en el congreso de Bad Godesberg (1959), mientras que el PSOE español tendría que esperar hasta el congreso de 1979 (tras la crisis del de 1976, con la dimisión de Felipe González como secretario general del mismo). La renuncia al marxismo era coherente con el giro que habíallevado a la socialdemocracia, tras la segunda guerra mundial, a apoyar decididamente la nueva modalidad de capitalismo, que en Europa continental dio origen al Estado de bienestar.

Este modelo era, en efecto, una alternativa, pero no al capitalismo en sí sino a una de sus formas históricas, el capitalismo liberal, el vigente hasta entonces. Esta modalidad nueva rompía la tradición marxista en una doble dirección: por una parte, parecía probar que Marx se había equivocado en sus análisis al no prever la capacidad de reacción del capitalismo desde dentro, incorporando una nueva variable a la actividad económica, los poderes públicos; por otra parte, el modelo naciente parecía garantizar una mayor atención a la igualdad básica de los ciudadanos mediante los mecanismos del Estado interventor y del Estado social. ¿Merecía la pena seguir aferrados al instrumental analítico y a la estrategia revolucionaria heredada de Marx? La socialdemocracia decidió que no, y además encontró el apoyo de otras fuerzas políticas e ideológicas, aunque lo hicieran por razones no siempre coincidentes. En el éxito del Estado de bienestar tuvo una función decisiva el llamado «consenso social-liberal», al que no faltó el apoyo ni de la democracia cristiana, que se comprometió seriamente en hacer avanzar el modelo, ni siquiera de los comunistas occidentales. 
Es indudable que el Estado de bienestar conoció un desarrollo espectacular desde el final de la segunda guerra mundial hasta fines de los 70, gracias no sólo al consenso político mencionado, sino también a las condiciones favorables de la economía de esos años: en efecto, el crecimiento económico sostenido permitió unir una alta retribución del capital, un aumento significativo de los niveles salariales y un incremento continuado de los recursos del Estado para hacer frente a las crecientes demandas sociales. Resultado: el consenso citado no quedó restringido a las fuerzas políticas, sino que fue compartido también por las fuerzas sociales. La mejora continuada del nivel de bienestar permitió una estabilidad social en llamativo contraste con el período de entreguerras y la crisis final del capitalismo heredado del siglo anterior.

Esta modalidad de capitalismo mixto, que es el Estado de bienestar, tuvo una implantación restringida. Su mejores realizaciones corresponden a los países industrializados, y más concretamente a los de Europa continental. En otros países, el distanciamiento del capitalismo liberal fue mucho más relativo: porque el Estado no intervino con la misma fuerza en todas las economías nacionales ni asumió en el mismo grado la cobertura de ciertas necesidades básicas de los ciudadanos. Se mezclaban aquí razones ideológicas (que explicarían, por ejemplo, las menores dimensiones del Estado social en países como Estados Unidos) y razones económicas (que se reflejan en las menores posibilidades de obtener recursos para el Estado en países con niveles más bajos de renta o resistencias mayores a la contribución fiscal).

\section{La «tercera vía», una respuesta a la crisis del estado del bienestar}

Este recorrido histórico era necesario para comprender la génesis de la «tercera vía». Porque ésta tiene que ver con el desarrollo y la crisis del Estado de bienestar, en las nuevas condiciones sociales yeconómicas del mundo a partir de la segunda mitad de los 70, y con el descalabro del modelo colectivista. Podemos adelantar que, en nuestra opinión, la «tercera vía» es un intento de respuesta a la crisis del Estado de bienestar, alternativa a la propuesta y desarrollada por el neoliberalismo tras la crisis de los 80. Por eso hay que preguntarse por el significado y alcance de la crisis de este modelo. 
No deja de ser sorprendente que un modelo que parecía haber alcanzado un fuerte consenso gracias a sus buenos resultados, en términos de bienestar e integración social, entrará desde finales de los 70 en una crisis cada vez más grave y evidente. ¿Qué puede explicarla?

Creemos que la crisis del Estado de bienestar obedece a dos tipos de razones: unas exógenas y otras endógenas.

Las causas exógenas responden a las nuevas coordenadas del mundo, que se han venido configurando desde la década pasada. Pueden sintetizarse en el término de globalización, que los franceses sustituyen por mundialización. Como fenómeno económico, la globalización significa que el referente que preside los análisis, proyectos y decisiones en ese ámbito ya no es el mercado nacional sino el mercado global. Eso ha sido posible gracias a los avances tecnológicos en el campo de la información y la comunicación, pero también como consecuencia de la desaparición de los bloques tras la caída del muro de Berlín. El proceso liberalizador promovido por el neoliberalismo ha encontrado en estas circunstancias, no sólo una justificación ideológica, sino importantes oportunidades técnicas.

La globalización, como reconoce el Programa de las Naciones Unidas para el Desarrollo (PNUD), es un fenómeno ambivalente, que tiene ganadores y perdedores y que en consecuencia hay que saber "gestionar». Pero entre sus efectos de mayor alcance se cuenta la pérdida de control de las economías nacionales por parte de los gobiernos. Esta circunstancia es clave para entender la crisis del Estado de bienestar: las exigencias de los mercados globales y de la competencia mundial restringen la capacidad de un gobierno para orientar la economía en función de los objetivos propios a su desarrollo político e institucional.

Las causas endógenas responden, en cambio, a la propia dinámica del Estado de bienestar. Por muy valiosos e irrenunciables que sean sus logros, hay que reconocer que el modelo ha ido derivando hacia situaciones cada vez más problemáticas. Los déficits públicos crecían deforma incontenible, mientras las

(1) Ya nos ocupamos de esta cuestión en otro editorial de nuestra revista: «Crisis y futuro del Estado de bienestar», Revista Fomento Social, no 198 (abril-junio 1995), pp. 149-169. 
posibilidades de aumentar los ingresos del Estado eran cada vez más exiguas. Detrás de esta dinámica insoportable se escondían las necesidades objetivas de atender a gastos en aumento por el alto nivel de desempleo y el envejecimiento demográfico, pero también las insaciables demandas de una sociedad más proclive a exigir prestaciones que a facilitar recursos con que cubrirlas. A ello se une la tendencia de los partidos políticos, siempre tentados de ganar votos a cambio de promesas de nuevas prestaciones. Y todo ello redunda en un crecimiento excesivo de la maquinaria de la administración pública, lo que reduce la eficiencia de su gestión y empaña su imagen social, sobre todo cuando aparece además como reducto para no pocos casos de corrupción.

He ahí, en pocas palabras, cómo las propias virtudes del Estado de bienestar parecen haberse vuelto contra él hasta convertirse, a veces, en vicios manifiestos. Su legitimidad queda, por consiguiente, cuestionada, precisamente por su notable incapacidad para seguir realizando las funciones que se le confiaron y que hasta hace unos años realizó de modo más que satisfactorio.

\section{El resurgir del liberalismo ante la crisis económica generalizada}

Este conjunto de circunstancias nuevas son las que explican el resurgir del liberalismo en estos últimos años: como marco general, la crisis económica y la progresiva globalización de la economía, así como la consecuente pérdida de competitividad de las economías más industrializadas; más en concreto, la crisis del Estado de bienestar, por su creciente incapacidad para mantenerse en este nuevo escenario.

Pero este resurgir no es una mera vuelta a los grandes maestros de antaño (Adam Smith, etc.), sino una verdadera radicalización de sus presupuestos en estas nuevas condiciones de un mundo globalizado: de ahí que sea más clarificador hablar de neoliberalismo, y no meramente de liberalismo. Sus propuestas se dirigen a todas las economías (ex-colectivistas, industrializadas avanzadas, subdesarrolladas). Independientemente del grado de desarrollo e intervención económica de los poderes públicos (muy diferente según países), el programa neoliberal siempre es el mismo: liberalización, desregulación, reprivatización, integración total en el único sistema económico mundial.

Este programa ha servido en algunos países para reconsiderar las dimensiones y las funciones del Estado, saliendo al paso de excesos evidentes a que se 
había llegado en las décadas recientes; en otros, donde el Estado tenía una actuación económica mucho más reducida o apenas existía, ha provocado ajustes muy duros.

El caso de Estados Unidos merece una palabra particular por su espectacular crecimiento económico en los últimos tres o cuatro años, frente al ritmo mucho más lento de los países de la Unión Europea. No cabe duda que Estados Unidos ejerce una hegemonía mundial que sus éxitos económicos refuerzan, especialmente en América Latina. Dicha hegemonía es absoluta a nivel militar, estratégico y cultural, pero incluso también económico: ni siquiera el prometedor nacimiento del euro es suficiente para negar que el dólar seguirá siendo una moneda más fuerte, aunque sólo sea por la superioridad fáctica del modelo de civilización «made in USA». Esta convicción es muy fuerte en el resto del continente americano, gracias al influjo de los modelos académicos norteamericanos, según los cuales se educaron las élites gobernantes y empresariales de muchos de aquellos países; y es compartida también por el pueblo, como lo manifiesta la extendida admiración por Miami y el deseo de tantos de vivir según el modelo que aquella ciudad simboliza.

Ante esta admiración tan difundida, Europa continental se debate entre sus menores logros económicos en términos comparativos y su empeño en conservar lo que de más valioso le aportó la tradición socialdemócrata: los derechos sociales. Este afán hacia lo que considera irrenunciable explica su resistencia a llegar a los extremos liberalizadores alcanzados en Estados Unidos. Por otra parte, no sería correcto ignorar los costes del paradigma neoliberal, que el mismo éxito norteamericano no puede ocultar. No son otros sino los ya conocidos de una economía casi totalmente confiada a los mecanismos del mercado: su tendencia a generar o ahondar las desigualdades sociales. Esto, que es experiencia de cualquier economía nacional de libre mercado sin restricciones, es mucho más grave cuando se trata del mercado mundial, donde las diferencias y desigualdades de partida son evidentemente mayores. Si la propuesta neoliberal ha servido para volver a la realidad desde los sueños de un Estado omnipotente (que derivó, en no pocas ocasiones, en simple paternalismo), tampoco es honesto que cerremos los ojos a la despreocupación neoliberal ante las desigualdades crecientes que su modelo produce. 
La «tercera vía» como alternativa a la solución neoliberal

Sinos hemos detenido en el análisis de la propuesta neoliberal y de sus efectos, es porque consideramos que es ahídonde nace la «tercera vía»: concretamente, desde la intención de oponerse a la solución neoliberal para la crisis del Estado de bienestar. Por tanto, es desde ahí desde donde conviene valorar sus posibilidades y limitaciones.

Más aún, el que sean tres importantes líderes europeos los que han comenzado a hablar de la «tercera vía» es signo evidente de que es un proyecto que ha nacido en Europa. Y ha sido presentado, según las declaraciones de sus promotores, como un intento de redefinición de la izquierda. Demos por bueno de entrada este dato, aunque luego tendremos que intentar una valoración del mismo.

Fue en febrero de 1998 cuando Tony Blair lanzó su propuesta de la «tercera vía». El primer ministro laborista anunció un ambicioso plan para agrupar e impulsar las fuerzas de centroizquierda a nivel mundial. Creía llegada la hora, de «diseñar y definir la ideología de centroizquierda para el mundo de hoy, y para ello pensaba en una tercera vía, superadora tanto de la «vieja izquierda» como de la «nueva derecha».

Poco después aparecería el libro de Anthony Giddens, La tercera vía. La renovación de la socialdemocracia. A este autor, que es actualmente director de la London School of Economics, se atribuye no sólo la paternidad de la expresión, sino la elaboración misma del proyecto. De entrada, el libro, a diferencia de las primeras manifestaciones de Tony Blair, centra su atención en Gran Bretaña, donde la socialdemocracia clásica (la vieja izquierda) ha sido sustituida por el neoliberalismo o thatcherismo (la nueva derecha).

Giddens compara esquemáticamente las características de una y otra, dejando ver de paso las diferencias que las separan, con el siguiente cuadro: 


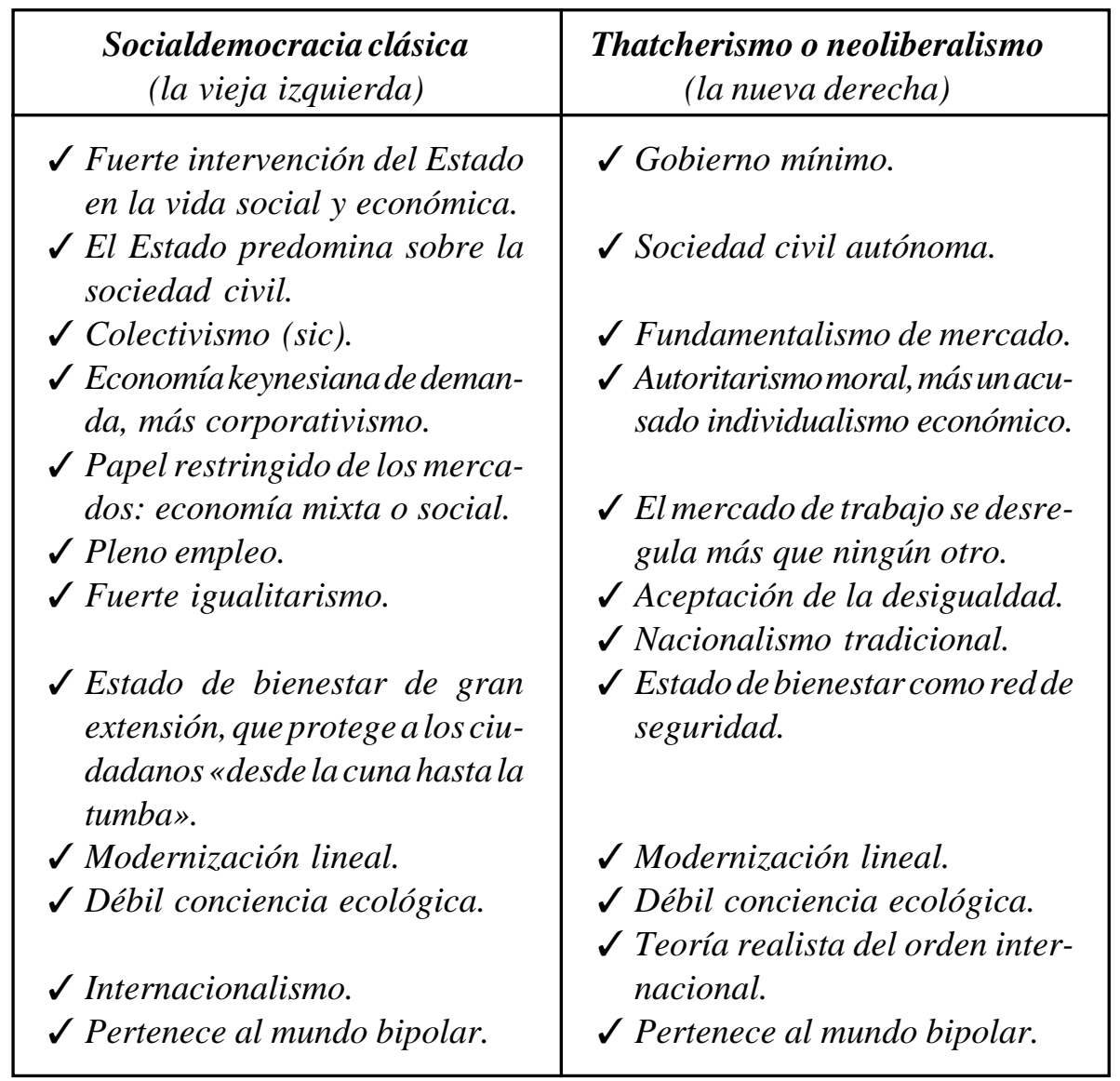

Renunciamos a entrar en el análisis de este cuadro comparativo para abordar el contenido de la propuesta de Giddens como nueva versión de la socialdemocracia (de la izquierda, para él) que se aleje del thatcherismo neoliberal. Dicha propuesta de la «tercera vía» se articula en cinco puntos.

1. El nuevo Estado democrático: el Estado sin enemigos. En opinión de Giddens el principal enemigo de la democracia es precisamente que no tiene enemigos. Esto exige un renovado esfuerzo por profundizar en las posibilidades de la democracia con prácticas que vayan más allá de la mera participación en las 
votaciones (democracia local directa, referendos electrónicos, jurados ciudadanos...). Hay que avanzar en la doble dirección: hacia abajo (descentralización) y hacia arriba (globalización). Esto supone aumentar el papel del Estado en la esfera pública, pero aumentando la transparencia y la imparcialidad.

2. Una sociedad civil activa. La cuestión básica en este punto es la asociación del gobierno y la sociedad civil para ayudarse y controlarse mutuamente. Esto supone renovar la comunidad mediante el aprovechamiento de la iniciativa social, favorecer el tercer sector y proteger la esfera pública local (reforzando las iniciativas, pero también corrigiendo los desajustes espontáneos). Aspecto importante aquí es la promoción de la familia democrática (favoreciendo en ella los elementos esenciales de la verdadera democracia: igualdad formal entre los sexos, derechos individuales, discusión pública de cuestiones sin violencia, autoridad apoyada más en la negociación que en la tradición).

3. Una nueva economía mixta. La clave aquí es la búsqueda de la sinergia entre sectores públicos y privados, así como el mantenimiento de la redistribución (que es un objetivo irrenunciable de la socialdemocracia), aunque poniendo ahora el énfasis en la redistribución de posibilidades. Estos presupuestos se concretan en una triple dirección:

$\left.1^{a}\right)$ La igualdad como inclusión, que se opone a la exclusión, tanto por arriba (exclusión voluntaria, la de los grupos más ricos que eligen vivir separados de la sociedad) como por abajo (exclusión involuntaria). Se considera un planteamiento más adecuado del tradicional principio de igualdad de oportunidades o meritocracia.

$\left.2^{a}\right)$ El bienestar como bienestar positivo: a partir de las críticas que se hacen hoy al Estado de bienestar hay que redefinir éste más como una mancomunidad de riesgos que de recursos: la gestión eficaz del riesgo no consiste sólo en minimizarlo o proteger contra él, sino en aprovechar su lado positivo y suministrar los recursos para la adopción del riesgo. Pero ese bienestar positivo no es sólo económico, es psicológico: el estar-bien. Por eso su principio guía ha de ser la inversión en capital humano, más que la provisión directa de sustento económico. Esta nueva forma de entender el bienestar, el bienestar positivo, «sustituiría cada aspecto 
negativo de Beveridge por uno positivo: en lugar de Indigencia, autonomía; no Enfermedad, sino salud activa; en lugar de Ignorancia, educación, como elemento duradero de la vida; en vez de Miseria, bienestar; y en lugar de Indolencia, iniciativa» [pág. 151].

$\left.3^{a}\right)$ El Estado social inversor. Aplicado al problema del desempleo masivo, esto significa que no basta la desregulación generalizada, como en Estados Unidos; que la política de empleo ha de ofrecer apoyo directo al empresariado para crear capital empresarial, impulsar la educación durante toda la vida, acrecentar la movilidad, compatibilizar el lugar de trabajo con la familia...

4. La nación cosmopolita. En la historia, la nación es un mecanismo integrador de la ciudadanía, pero el nacionalismo resulta muchas veces beligerante. Se precisa hoy una versión más cosmopolita de la nacionalidad. El Estadofuerte no debería entenderse como el que está bien pertrechado para la guerra, sino como la nación suficientemente segura de sí misma como para aceptar los nuevos límites a la soberanía que impone la globalización. Y globalización no equivale a internacionalización: no significa sólo lazos más estrechos entre las naciones, sino procesos que traspasan las fronteras nacionales. La nación cosmopolita es una nación activa: no construida desde el antagonismo hacia otros, sino desde la tolerancia hacia el entorno y la aceptación de otras lealtades paralelas.

5. Democracia cosmopolita. El panorama mundial ha cambiado (ya no es tan probable una guerra generalizada, salvo accidentes, ya no hay bloques, importan menos el territorio y los recursos naturales que la capacidad competitiva, la soberanía se ha vuelto confusa y múltiple) evolucionando hacia una sociedad global que funciona a escala global, es necesario un gobierno global con nuevas instituciones: una asamblea parlamentaria mundial (con miembros elegidos por los parlamentos nacionales), un tribunal de justicia efectivo... Sólo una democracia cosmopolita será capaz de regular la economía mundial y hacer frente al fundamentalismo del mercado. 
Variantes dentro de la «tercera vía»: Clinton, Blair y Schröder, Jospin

Si Blair es el iniciador, no ha sido el único promotor de la idea. Ya en 1998, en julio concretamente, Hillary Clinton invitó a un encuentro en la Casa Blanca a una quincena de miembros de los grupos de intelectuales y expertos del Partido Demócrata para discutir qué políticas, principios y valores distinguían a su partido del republicanismo. Buscaban los puntos de convergencia entre los demócratas más tradicionales y los nuevos demócratas (de talante más liberal). Todo ello no era ajeno al objetivo de lanzar un nuevo mensaje, coherente y movilizador, en su combate político contra la derecha, en los Estados Unidos y en el mundo. En el desarrollo de las discusiones se aludió repetidas veces al proyecto de Blair y a sus posibilidades dentro de los Estados Unidos y a escala internacional.

Todo ello culminó en un encuentro internacional, celebrado el 21 de septiembre de 1998 en la Universidad de Nueva York, bajo el lema «Reforzando la democracia en la economía global», que se inscribía en el contexto de lanzamiento de llamado movimiento de la «Third Way»). Asistieron Bill Clinton, Tony Blair, Romano Prodi y el presidente búlgaro, Peter Stoyonov. Declinaron la invitación Lionel Jospin y Fernando Henrique Cardoso.

Es indudable que estos encuentros tienen una clara intención de operación política, que en el caso de Clinton coincide además con los momentos más delicados del caso Lewinski. Pero las figuras de Gerhardt Schröder en Alemania y de Lionel Jospin en Francia merecen una atención por sus esfuerzos por marcar las distancias con los gobiernos de centro-derecha que les precedieron

Es cierto que Schröder se encontró pronto serias dificultades a su proyecto: no sólo el hecho de tener que gobernar en coalición con los Verdes, sino además la oposición del ala más radicalmente izquierdista de su propio partido protagonizada por el que fue ministro de finanzas en su primer gobierno, Oskar Lafontaine (a su libro anterior a la victoria socialdemócrata, No hay que tener miedo a la globalización. Bienestar y trabajo para todos, de fuerte crítica a la democracia cristiana de Helmut Kohl, ha seguido, tras su dimisión y alejamiento respecto de Schröder, el más reciente, El corazón late a la izquierda). Los sucesivos descalabros electorales a nivel regional no auguran un futuro muy prometedor a su proyecto socialdemócrata renovado.

Lionel Jospin se ha esforzado en todo momento por mantenerse a una 
prudencial distancia de sus homólogos europeos. Su situación es distinta, tras el fracaso de Jupé. Su estrategia es otra también: lo más significativo en ella es su marcado realismo, que le permite avanzar con algunas decisiones emblemáticas (la jornada de 35 horas) al tiempo que transige con la dura realidad, sobre todo en el caso de los ajustes de plantillas de las grandes empresas...

Esta distancia de Jospin respecto a Blair y Schröder ha quedado confirmada en estos últimos meses con el manifiesto conjunto presentado el día 8 de junio por estos dos últimos Europa: la tercera vía, el nuevo centro. No sólo no fue suscrito por el primer ministro francés, sino que que esta iniciativa anglo-alemana, que pretendía hermanar el «Nuevo Centro» de Alemania y la «Tercera Vía» del Reino Unido, provocó un abierto malestar entre los socialistas franceses. A pesar de estas disidencias, el citado manifiesto merece ser estudiado con atención como un nuevo paso de llenar de contenido la oferta de la «tercera vía». El texto arranca una vez más de un balance del pasado para extraer las lecciones pertinentes. Destaca en este examen la constatación de que la excesiva confianza en el Estado, al que se asignó demasiado protagonismo, ha producido una preocupante desmovilización de la sociedad. Esta autocrítica explica las dos grandes líneas del proyecto que Blairy Schröder patrocinan bajo la denominación de «Programas nuevos para realidades nuevas»:

$\checkmark$ Una política económica más centrada en la oferta (subrayando que estas políticas de oferta son complementarias de las políticas de demanda, en las que insistió casi exclusivamente la tradición socialdemócrata). De acuerdo con este nuevo enfoque, se pone el acento en la adaptabilidad y la flexibilidad de los recursos productivos y en la reducción de la presión fiscal para dejar más iniciativa al sector privado. Todo ello se traduce en la necesidad de redefinir el papel de un Estado activo.

$\checkmark$ Una política laboral activa. El Estado no ha de limitarse a restañar las heridas del desempleo o los fracasos económicos: tiene que promover activamente la creación de empleo, lo que exige una decidida apuesta por la inversión en capital humano y social como prioridad indiscutible.

Quizás la insistencia en la palabra «activo» (que aparecía también en la obra de Giddens) es el rasgo más distintivo de este programa: la actuación del Estado no puede provocar una postura pasiva (la propia del que recibe prestaciones), 
sino que tiene que estimular la actividad y la iniciativa de todos los que se benefician de ella; en otras palabras, la acción del Estado no puede sustituir a la de los particulares, sino que tiene que potenciarla.

\section{Una valoración de la tercera vía}

Hasta ahora nos hemos mantenido en un terreno casi estrictamente descriptivo. Pero ahora llega el momento más delicado de tomar postura frente a este nuevo movimiento que se presenta como «tercera vía».

¿Cuáles son los objetivos y metas de la «tercera vía»?

Comencemos por las intenciones. Luego veremos si las realizaciones se corresponden con lo pretendido...

$Y$ si hay que hablar de intenciones, la primera a mencionar es la que expresamente invocan sus promotores: una reformulación de la socialdemocracia, que sea alternativa a la propuesta neoliberal. Esto significa tres cosas, implícitas en el nuevo proyecto:

$\checkmark$ Que se admite la inviabilidad del Estado de bienestar en las actuales condiciones de la sociedad y después de las incoherencias a que él mismo ha dado lugar ( $f$ frente a la vieja izquierda»).

$\checkmark$ Que no se admite la fórmula neoliberal porque, a pesar de su crítica certera en muchos puntos de la crisis del Estado de bienestar, propone medidas que contradicen de modo escandaloso lo más esencial de la tradición socialdemócrata ( frente a la nueva derecha»).

$\checkmark$ Que las nuevas condiciones de una sociedad globalizada exigen replantear el alcance y modalidades de la intervención económica del gobierno.

Esta propuesta ha nacido en Europa, aunque haya sido apoyada por Clinton y su staff más cercano. Aunque tiene pretensiones de alcance universal (como nuevo banderín de enganche para toda la izquierda), su cuna es geográficamente limitada: por eso responde esencialmente al estado de cosas que se da en Europa continental.

Por otra parte tiene una fuerte carga electoralista. Para muchos se agota en eso: no es más que una nueva versión de ese discurso electoral ávido de afirmaciones espectaculares, pero de una total pobreza de contenidos. El 
desencanto del electorado respecto a los partidos tradicionales, que parecen decididos a abandonar poco a poco todas las conquistas del Estado de bienestar, era una buena coyuntura para intentar una vía novedosa. A ello contribuiría este nuevo ciclo político europeo que abre nuevas posibilidades a la izquierda o al centro-izquierda como consecuencia de un cierto agotamiento de la alternativa neoliberal: ¿en cuántos países de la Unión Europea han accedido al gobierno en los últimos años partidos de centro-izquierda? Y tampoco podría ignorarse, como nuevo síntoma del agotamiento citado, las sucesivas crisis en los mercados financieros mundiales, que parecen poner en cuestión el fundamentalismo del mercado, unos de los pilares del neoliberalismo.

Todas estas circunstancias hay que considerarlas conjuntamente para hacernos una idea cabal de la tercera vía. De ellas se deriva una sensación de ambivalencia, con un aspecto inicialmente positivo, el más positivo del conjunto: su no resignación ante el pensamiento único. La sola propuesta implica un no rotundo a admitir el modelo de economía liberal y cada vez más liberalizada como la única vía pensable tras el fracaso del colectivismo y la crisis del Estado de bienestar. Interesarse por la «tercera vía» significa no admitir la pretensión de Francis Fukuyama, del fin de la historia. Pero ello no obsta para reconocer que a la «tercera vía» le falta la consistencia que alcanzó el movimiento neoliberal en los años $80 . .$.

Si esta intención, a pesar de sus contaminaciones de oportunismo electoral, es suficiente para mirar con curiosidad e interés la propuesta, es preciso ahondar más en sus contenidos. Sólo así cabe llegar a un juicio más equilibrado.

¿Propuesta de izquierda?

Es difícil afirmarlo. El mismo Giddens prefiere hablar de izquierda del centro, mejor que de centro-izquierda... ¿Significa esto una renuncia definitiva a los ideales esencialmente de igualdad que han servido como seña de identidad tradicionalmente a la izquierda?

Desde luego la izquierda más coherente se sentirá incómoda frente a la tercera vía. Ya se sintió con la socialdemocracia, cuando ésta renunció a su rechazo del capitalismo y optó por suavizar su dinámica generadora de desigualdades... Hoy la tercera vía sigue apostando confiadamente, en línea con lo mejor de la tradición socialdemócrata, por la profundización de la democracia, conjugan- 
do el sistema socioeconómico y el sistema político. Pero esto es precisamente lo que la izquierda siempre recriminó a esta corriente nacida del socialismo. Y la Escuela de Frankfurt-Habermas, más concretamente-lo ha vuelto a hacer con redoblada insistencia desde los años 70 (véase su Problemas de legitimación en el capitalismo tardío): que las exigencias del sistema económico capitalista son incompatibles con la democracia porque es imposible el equilibrio entre la acumulación capitalista y el ejercicio efectivo de las libertades. Desde esta óptica, el Estado de bienestar queda reducido a un puro espejismo transitorio, que se amparó en la bonanza económica de un periodo muy concreto de la historia del presente siglo.

Si la socialdemocracia inspiraba ya desconfianza a muchos representantes de la izquierda, ¿cuánto más esta nueva versión aún más atenuada?

Lo que tienen que reconocer los críticos de la izquierda es que las condiciones de un mundo globalizado obliga a replantear las posibilidades de todo proyecto de izquierda. Este condicionamiento insoslayable explica muchas políticas económicas ortodoxas aplicadas en estos años, incluso por gobiernos que se llamaban socialistas, como la única vía para mantener unos niveles de competitividad en todos los mercados de los factores de producción. Lo único que cabe preguntar todavía es si esas políticas económicas más ortodoxas permiten mantener los logros más emblemáticos del Estado del bienestar o nos obligan a renunciar a ellos.

De las intenciones de la «tercera vía» a las propuestas concretas

Cuando nos interesamos por la fidelidad de la «tercera vía» a la tradición de la izquierda no nos mueve ningún prurito de progresismo, sino el deseo de que no se pierdan en el bosque de las grandes declaraciones lo que ha sido su principal aportación histórica. Si tradicionalmente la derecha se ha asociado a los valores de la libertad y a la producción económica, la izquierda se ha definido por los valores de la igualdad y de la distribución. El socialismo liberal o el consenso social-liberal buscaron una cierta síntesis de ambos: se apoyaba en la convicción de que a la larga no queda garantizada una verdadera libertad para todos si no existe una cierta igualdad.

Pero la «tercera vía» no concede una excesiva importancia a la distribución, sobre todo si se tiene en cuenta que la etapa de vigencia del neoliberalismo ha 
desequilibrado todas las sociedades aumentando los niveles de desigualdad. Esa es la consecuencia del fundamentalismo del mercado. La cuestión es, como lo fuera en la crisis del capitalismo liberal, cómo controlar el libre mercado para reducir sus disfunciones. Pero aquí nos topamos con una «tercera vía» fuertemente marcada por el miedo al Estado, heredado de la etapa anterior. El analizar con lupa las partidas de gastos sociales o las continuas recomendaciones a disminuir la presión fiscal para estimular el crecimiento económico nos devuelve a la teoría del efecto rebalse: si se acelera el crecimiento, a la larga todos se benefician, aunque a corto plazo la distribución de sus frutos sea menos satisfactoria para todos.

Es cierto que la «tercera vía» apenas hace mención del concepto de libertad. Pero ¿en qué se está pensando, sino en ella, cuando se exalta el mercado y la competencia o se confía al crecimiento económico el bienestar de todos? La apuesta por una profundización en la verdadera democracia es esencial en este contexto, ¿pero está suficientemente dotada de instrumentos eficaces en una sociedad tan confiada a la lógica del mercado?

El malestar de la sociedad actual tiene que ver con un deterioro en la distribución. Resurge así el conflicto social, que parecía algo superado en una sociedad crecientemente integrada. Y sin embargo la izquierda viene negando o ignorando desde hace décadas cualquier atisbo de conflictividad, a pesar de que ésta ha caracterizado desde siempre a la sociedadmoderna. La «tercera vía» en esto no ha hecho sino seguir la senda de la izquierda que le precedió... ¿No puede encontrarse aquí una causa probable de la pérdida de apoyo popular que está sufriendo la izquierda?

Si esta hipótesis es válida, se confirmaría el carácter electoralista del proyecto de la «tercera vía». Pero en un sentido enormemente peligroso. Porque supondría el abandono de los que viven en la exclusión (de las víctimas de este crecimiento vertiginoso confiado al torbellino de los mercados abiertos y competitivos) y el intento de atraer el voto de un colectivo numéricamente más apetitoso: la nueva clase media, eso que Galbraith denominaba la «mayoría electoral satisfecha» en su obra La cultura de la satisfacción. En ese sentido es reveladora la propuesta de Giddens cuando habla de la izquierda del centro... Pero habría que preguntar: ¿qué queda de los ideales de la izquierda cuando emigra hacia el centro y se vuelve ciega para los que están más allá de los márgenes? ¿Es que, a medida que son más los que se incorporan a la sociedad 
acomodada, aun en tiempos de crisis, es menos plausible un proyecto político que se ocupe de los pobres? ¿No revela esto en toda su crudeza hasta qué punto pueden quedar vacíos de contenido los ideales democráticos a manos de las implacables leyes de las matemáticas electorales? ¿O tendríamos que resignarnos a alabar la fortaleza de la institucionalidad democrática en Europa, aunque sólo sea por su capacidad para dar cabida a opciones políticas que acaban siendo sumidero de las frustraciones de tantos ciudadanos?

En resumen, si la meta de una mejor distribución se desvanece o se difumina, el apelar a los ideales de la izquierda empieza a ser sospechoso de ideológico, en el peor sentido de esta palabra. Denominaciones políticas aparte (izquierda, centro o derecha...), este nuevo proyecto poco de nuevo tendrá que aportarfrente al neoliberalismo dominante. Quedará reducido a una estrategia electoral más, concebida para conquistar votos y no para transformar la sociedad.

\section{Más allá de la «tercera vía»: las dimensiones mundiales del problema}

Lo hemos dicho varias veces a lo largo de las páginas que preceden: la «tercera vía» es una propuesta pensada desde los países industrializados y para ellos. Esta es una nueva limitación real del proyecto. Como conclusión de nuestras reflexiones quisiéramos detenernos en este hecho y en algunas de sus consecuencias. Esencialmente nos referiremos a dos.

Cabe preguntar, en primer lugar, si la «tercera vía» es un proyecto extrapolable. Al fin y al cabo, son muchos los países del tercer mundo que están necesitados de una alternativa porque el modelo neoliberal, que terminó imponiéndose en ellos como consecuencia de la crisis del estructuralismo y/o del populismo, ha acarreado costes considerables.

No estamos seguros de que la tercera vía aporte mucho a estos países, entre otras razones porque en ellos el punto de partida para una reconstrucción o un redimensionamiento del Estado es muy distinto, y porque nunca ha existido un mecanismo creíble, consensuado y estable con el que la sociedad civil pudiera condicionar la acción de sus respectivos gobiernos... Sólo cabría aprovechar las sinergias derivadas de ese esfuerzo por buscar alternativas al modelo neoliberal de veneración por el mercado y alergia hacia el Estado, buscando así una convergencia de la izquierda a nivel mundial.

La segunda pregunta es de más alcance: ¿hasta qué punto en el proyecto de 
la «tercera vía» hay una consideración suficiente del contexto mundial, que aborde las responsabilidades de los países ricos frente a los del tercer mundo? Si a la pregunta anterior respondíamos con cierto escepticismo, ahora lo hacemos de forma casi totalmente negativa. La izquierda, al menos la izquierda europea, a pesar del internacionalismo obrero de Marx, no se ha caracterizado históricamente por una atención prioritaria a los problemas del tercer mundo, aunque haya apoyado movimientos revolucionarios en África, Asia o América Latina. Pero hoy no deja de causarnos estupor este ensimismamiento de la tercera vía que le lleva a dejar fuera de su consideración a más de tres cuartas partes de la humanidad.

¿Podría incluirse en el haber de esta cuestión las propuestas de una ciudadanía universal o de una sociedad civil mundial? Sin duda, pero reconociendo inmediatamente la imprecisión de este concepto.

En todo caso, el fundamentalismo del mercado causa muchos más estragos a escala mundial y dentro de los países más atrasados, cuando se integran en él, que en las naciones industrializadas. Cualquier proyecto concebido desde los ideales de la izquierda debe asumir responsablemente este hecho para incluir propuestas tendentes a controlar ese mercado global. Sin duda que aquí las vías concretas son mucho más problemáticas, ya que no existe un equivalente al poder coactivo del Estado que, a escala mundial, sea capaz de contrarrestar a las fuerzas del mercado. Por otra parte, crece el consenso en torno a la necesidad de alguna regulación de los mercados mundiales-sobre todo, tras las recientes crisis en los mercados financieros-.

\section{Postcriptum}

A punto ya de enviar estas páginas a la imprenta se produce un acontecimiento que nos invita a completar estas últimas conclusiones con algunos matices más esperanzadores. Nos referimos a la celebración del XXI Congreso de la Internacional Socialista y a la «Declaración de París», que se aprobó durante su celebración, el día 8 de noviembre pasado.

Ante todo, parece que fue la ocasión para un reencuentro de Lionel Jospin con el eje anglo-alemán y su manifiesto de junio. El cuidado, tanto de Blaircomo de Schröder, por evitar toda referencia a términos como «liberalismo»o «flexibilidad» contribuyó a tranquilizar a sus compañeros franceses. 
Pero no es ése el aspecto que más nos interesa destacar del citado congreso. Es más importante la perspectiva internacional que dominó en él, en contraste con lo que hemos venido advirtiendo en todas las propuestas de la «tercera vía». El hecho de que en París se dieran cita representantes de 143 partidos de todo el mundo tiene que ver, sin duda, con este cambio de horizonte.

Hay que comenzar subrayando que la «Declaración de París» reclama la supremacía de la política sobre el mercado. Y esto se aplica especialmente al ámbito mundial, donde se aboga por la reforma de los organismos financieros y económicos internacionales (como el Fondo Monetario Internacional, el Banco Mundial y la Organización Mundial de Comercio), así como por la creación de un nuevo marco jurídico internacional que permita controlar los movimientos del capital financiero y luchar eficazmente contra los efectos negativos de la globalización.

Nosotros queríamos terminar estas páginas reivindicando una autoridad mundial que intente poner orden en ese caos que es el mercado global. Ahora nos congratulamos al ver que la Internacional Socialista hace propuestas en esa línea y que la izquierda parece reavivar hacia la memoria de su herencia internacionalista. No es el momento de entrar en el análisis de las fórmulas concretas, algunas de las cuales circulan ya en los debates de los foros internacionales. Nos contentamos, para terminar, con hacer una llamada a la voluntad política, que tanto se echa de menos a la hora de lle gar a compromisos intergubernamentales efectivos. Y lo hacemos pensando en dos hechos de actualidad inmediata: la nueva ronda de negociaciones en la Organización Mundial del Comercio; la demanda, cada vez más fuerte, de llegar a acuerdos multilaterales que sometan a cierto control los mercados financieros mundiales. ¿No estamos ante dos ocasiones de oro para que la izquierda recupere la legitimidad que está perdiendo por su debilidad en defender los ideales de igualdad y justicia, y especialmente de justicia internacional? Y volviendo al tema de nuestro editorial, ¿no serían también estas dos oportunidades inmejorables para que la «tercera vía» se cuestione más eficazmente las responsabilidades de estos países ricos respecto a los pueblos más atrasados del planeta? 